\title{
Phase II study of an AKT inhibitor MK2206 in patients with relapsed or refractory lymphoma
}

\author{
Yasuhiro Oki ${ }^{1}$, Michelle Fanale ${ }^{1}$, Jorge Romaguera ${ }^{1}$, Luis Fayad ${ }^{1}$, Nathan Fowler ${ }^{1}$, Amanda \\ Copeland ${ }^{1}$, Felipe Samaniego ${ }^{1}$, Larry W. Kwak ${ }^{1}$, Sattva Neelapu ${ }^{1}$, Michael Wang ${ }^{1}$, Lei \\ Feng $^{2}$, and Anas Younes ${ }^{1}$ \\ ${ }^{1}$ Department of Lymphoma/Myeloma, The University of Texas, M.D. Anderson Cancer Center, \\ Houston, TX, USA \\ ${ }^{2}$ Department of Biostatistics, The University of Texas, M.D. Anderson Cancer Center, Houston, \\ TX, USA
}

\section{Summary}

We conducted a phase II study of the AKT inhibitor, MK2206 in patients with relapsed or refractory lymphoma of any histology excluding Burkitt lymphoma or lymphoblastic lymphoma. MK-2206 was administered orally at $200 \mathrm{mg}$ once weekly in 28-d cycles up to 12 cycles in the absence of progression or significant toxicity. The dose was adjusted based on tolerance. A total of 59 patients were enrolled. The final doses patients received were $300 \mathrm{mg}(n=33), 250 \mathrm{mg}(n=2)$, $200 \mathrm{mg}(n=16)$ and $135 \mathrm{mg}(n=8)$. Based on intent-to-treat analysis, objective response was observed in $8(14 \%)$ patients ( 2 complete response and 6 partial response), with median response duration of 5.8 months. The overall response rate was $20 \%$ in 25 patients with classical Hodgkin lymphoma. Rash was the most common toxicity (any grade 53\%, Grade 3 in 15\%) and was observed in a dose-dependent manner. The correlative cytokine analysis showed paradoxical increase in several cytokines, which may be explained by negative feedback mechanism induced by the on-target effect of AKT inhibitor. Our data demonstrate that MK2206 has a favourable safety profile with a modest activity in patients with relapsed Hodgkin lymphoma. The future studies should explore mechanism-based combinations (clinicaltrials.gov NCT01258998).

\section{Keywords}

lymphoma; clinical trials; target therapy; AKT

The phosphoinositide 3-kinase (PI3K)/AKT/mechanistic mammalian target of rapamycin (mTOR) signalling pathway plays a central role in regulating cell survival and proliferation

Correspondence: Anas Younes, Lymphoma Service, Memorial Sloan-Kettering Cancer Center, 1275 York Avenue, Box 330, New York, NY 10065, USA. younesa@mskcc.org.

Authorship contributions

Y.O. collected data, analysed data, provided patient care and wrote the paper. M.F., J.R., L.F., N.F., F.S., L.W.K., S.N., and M.W. provided patient care and edited the paper. A.C. provided patient care and collected data. L.F. designed study and analysed data. A.Y. designed and supervised the clinical trial, provided patient care, analysed data and wrote the paper.

Conflict of interest statements

Authors disclosed no conflict of interest. 
(Georgakis \& Younes, 2006; Jia et al, 2008). Constitutive activation of this pathway has been observed in a variety of cancers, including classical Hodgkin lymphoma (cHL) and nonHodgkin lymphoma, and is implicated in promoting cancer cell growth and survival (Vivanco \& Sawyers, 2002; Osaki et al, 2004; Hay, 2005; Jia et al, 2008; Yuan \& Cantley, 2008; Engelman, 2009).

Inhibition of PI3K, AKT or mTOR kinases have been shown to confer anti-proliferative effect and apoptosis in a variety of lymphoma types in vitro (Vivanco \& Sawyers, 2002; Osaki et al, 2004; Hay, 2005; Georgakis \& Younes, 2006; Jia et al, 2008; Yuan \& Cantley, 2008; Engelman, 2009). Based on these studies, novel agents that target this pathway have been tested in clinical trials for relapsed or refractory lymphomas. The first agents tested in clinical trials were the mTOR inhibitors, everolimus and temsirolimus. Although mTOR inhibitors demonstrated clinical activity with response rates up to $35 \%$, treatment was associated with Grade 3/4 thrombocytopenia (>30\%). (Yee et al, 2006; Witzig et al, 2011; Johnston et al, 2012a; Renner et al, 2012) There are multiple potential reasons for mTOR inhibitors to have limited clinical activity. First, mTOR only weakly induces apoptosis but predominantly induces cell cycle arrest and autophagy. Second, mTOR inhibitors frequently activate phosphorylated AKT by a feedback loop, presumably by TOR complex 2, which in turn attenuates the antitumour effect. Therefore, targeting upstream molecules, such as AKT or PI3K may be more advantageous. In fact, PI3K and AKT inhibitors are more potent apoptosis-inducers than mTOR inhibitors in vitro.

PI3K inhibitors, such as idelalisib, duvelisib, buparlisib and BAY80-6946, have shown clinical activity in lymphoma (Rodon et al, 2013). There has however been no clinical data with AKT inhibitors in lymphoma. MK-2206 is the first allosteric inhibitor of AKT to enter clinical development, with a nanomolar inhibitory potency against AKT1 and AKT2. MK-2206 demonstrated AKT inhibition and antiproliferative activity as single agent and in combination with other agents in multiple human cancer cell lines. MK-2206 synergized antitumour effects of chemotherapeutic agents in vivo and in vitro (Hirai et al, 2010; Li et al, 2012) and may overcome mTOR inhibitor resistance in B-cell lymphoma (Petrich et al, 2012). Based on such clinical data, MK-2206 has been tested clinically as a single agent in advanced solid tumours (Yap et al, 2011) or acute myeloid leukaemia (Konopleva et al, 2014) and in combination with chemotherapy (Molife et al, 2014). MK-2206 was well tolerated, with evidence of AKT signalling blockade in these studies. We conducted a phase II study of MK2206 in patients with relapsed or refractory lymphoma, to assess the activity and safety of this agent. In this study, weekly dosing of MK-2206 was explored based on the result of phase I study showing sustained AKT blockade and a pharmacokinetic profile of weekly dose of MK2206 (Biondo et al, 2011).

\section{Materials and methods}

This was an open-label, single arm phase II study of MK-2206 in patients with lymphoma. This study was approved by the institutional review board, and was registered at clinicaltrias.gov (identifier NCT01258998). All patients enrolled in this study gave written informed consent. The primary objective of the study was to determine the overall response rate [complete response (CR) plus partial response (PR)]. The secondary objectives included 
evaluation of the safety profile of MK-2206 and determination of the event-free survival (EFS) of MK-2206.

\section{Eligibility}

Eligible patients were required to have lymphoma of any histology, excluding Burkitt lymphoma or lymphoblastic lymphoma, that had relapsed or been refractory after at least one treatment regimen and have no curative option available. Other inclusion criteria included: $\geq 18$ years of age; measurable disease $\geq 2 \mathrm{~cm}$; Eastern Cooperative Oncology Group Performance Status 0-1; absolute neutrophil count $\geq 1.5 \times 10^{9} / 1$; platelet count $\geq 75 \times$ $10^{9} / 1$; serum creatinine $\unlhd 1.5 \times$ upper limit of normal (ULN); total bilirubin $\unlhd .5 \times$ ULN ( $3.0 \times$ ULN if lymphomatous involvement in the liver); transaminase levels $\_.5 \times \mathrm{ULN}$ ( $5.0 \times$ ULN if lymphomatous involvement in the liver); and glycated haemoglobin (HbA1c) $\$ 8 \%$. Patients were ineligible if they were pregnant, had received chemotherapy or radiotherapy within the 3 previous weeks, had human immunodeficiency virus infection, active viral hepatitis, impaired cardiac function (QTc $>450 \mathrm{~ms}$, heart rate $<50 \mathrm{bpm}$ ) or were on medications that are known strong inhibitors of CYP4503A4.

\section{Treatment and toxicity assessment}

Based on preclinical and clinical experience, weekly oral dosing was considered adequate in achieving peak target inhibition and also better tolerated than more frequent dosing, such as daily or every other day dosing (Biondo et al, 2011). In this study, MK-2206 was administered orally once weekly in 28-d cycles up to 12 cycles in the absence of progression or significant toxicity. The initial dose in this study was $200 \mathrm{mg}$, to be administered at least 2 $\mathrm{h}$ before or after a meal. Toxicity was graded based on Common Terminology Criteria for Adverse Events Version 4 (http://evs.nci.nih.gov/ftp1/CTCAE/

CTCAE_4.03_2010-06-14_QuickReference_8.5x11.pdf). If a patient experienced toxicity of Grade 3 or greater, the dose was interrupted until the toxicity decreased to Grade 1 or better, or to baseline, and the patient resumed treatment at a lower level, according to Table I. If a patient experienced Grade 2 toxicity that was considered unacceptable by the patient or the treating physician, the dose could be reduced in a similar fashion. The dose interruption was allowed for up to 3 weeks. Patients were withdrawn from the study if the toxicity did not recover to Grade 2 or better (or within 1 grade of starting values for pre-existing laboratory abnormalities) from a treatment-related toxicity. Once a dose was decreased, it could not be increased at a later time. On the other hand, if, after 2 weeks of treatment, a patient did not experience any treatment-related toxicities $\geq$ Grade 2 , the dose could be escalated to the next dose level, according to Table I. If after another 2 weeks of therapy no Grade 2 or higher related toxicities were experienced, the dose level could be increased again to the next higher dose level.

The inhibition of glucose transport into the cell by AKT/mTOR inhibitors may render insulin ineffective. According to the protocol, Grade 3 hyperglycaemic events ( $>13.875$ $\mathrm{mmol} / \mathrm{l}$ ) should lead to consultation with an endocrinologist. If glucose levels did not return to Grade 1 or lower within 1 week of appropriate therapy, patients should have a dose modification. The goal of therapy was to keep fasting glucose $<8.325 \mathrm{mmol} / \mathrm{l}$, random blood glucose levels $<10 \mathrm{mmol} / \mathrm{l}$, and $\mathrm{HbA} 1 \mathrm{c}<8 \%$. Glucose monitoring was performed weekly, 
during the first cycle of therapy, and on day 1 of subsequent cycles, prior to drug administration.

\section{Response assessment}

Response assessment was performed every 2 cycles of therapy using the Cheson et al (2007) criteria, and the response was coded as CR, PR, stable disease or progressive disease. In patients who had bone marrow involvement at the time of enrolment, bone marrow evaluation was repeated when radiographically in CR. After discontinuation of therapy, patients were followed every 3 months for the first 2 years, then every 6 months thereafter, or until progression.

\section{Statistical consideration}

Patients were enrolled separately for the following five histology cohorts: (i) relapsed or refractory cHL, (ii) indolent lymphoma, (iii) diffuse large B cell lymphoma (DLBCL), (iv) mantle cell lymphoma (MCL) and (iv) peripheral T-cell lymphoma (PTCL). The primary endpoint was the objective response rate (ORR) at 4 months. The target response rate for each histology cohort was 30\%, 50\%, 40\%, 30\% and 30\%, respectively. A response rate lower than $10 \%, 30 \%, 20 \%, 10 \%$ and $10 \%$, respectively, was considered a failure. A Simon's MiniMax two-stage design was used for each cohort with alpha $=0.1$ and beta $=$ 0.1 . In the first stage, $2 / 16,8 / 28,4 / 19,2 / 16$ and $2 / 16$ responses were required to continue each cohort to the second stage, respectively. Total responses of 5/25, 16/39,11/36, 5/25 and $5 / 25$ respectively in each cohort were considered sufficiently active to warrant further study.

Response duration was calculated from the first day of documented response to the day of disease progression. EFS ass calculated from the day of study enrolment to the day of documented disease progression, change in treatment to a different regimen or death from any cause. For response duration and EFS, patients who proceeded to stem cell transplant after this treatment was censored at the time of such decision.

\section{Correlative cytokine analysis}

Serum cytokines levels are measured in consenting patients on days 1,8 and 22 of the first cycle. Twenty-nine cytokines were analysed including VEGF, EGF, Eotaxin, G-CSF, GMCSF, IFN-a2, IFN- $\gamma$, IL1a, IL1 $\beta$, IL1Ra, IL2, IL3, IL4, IL5, IL6, IL7, IL8, IL10, IL12 (p40), IL12 (p70), IL13, IL15, IL17, IP10, MCP1, MIP1a, MIP1 $\beta$, TNFa, and TNF $\beta$. Serum cytokines and chemokine were measured using the Human Cytokine/Chemokine Magnetic Beads Panel kits (Cat. No. HCYTMAG-60K-PX29; Millipore, Billerica, MA, USA) on Luminex-100 ELISA System (Luminex Corporation, Austin, TX, USA). This was an exploratory analysis and the results are shown descriptively. Significance of the changes in the cytokine levels from baseline was analysed by Wilcoxon signed rank test. $P$ values < 0.05 were considered statistically significant. 


\section{Results}

\section{Patient characteristics}

Between January 2011 and November 2012, 59 patients were enrolled. Cohort 1 (cHL) enrolled 25 patients as planned. Other cohorts, however, were closed early due to lack of response. Table II lists the baseline characteristics of these patients. Overall, this was a heavily treated population with median number of prior treatment regimen of 4 (range 110); 24 (48\%) had undergone stem cell transplantation.

\section{Treatment dose and duration}

The protocol allowed a dose adjustment based on tolerance and toxicity. The final dose that patients received were $300 \mathrm{mg}(n=33), 250 \mathrm{mg}(n=2), 200 \mathrm{mg}(n=16)$ and $135 \mathrm{mg}(n=$ 8 ). The median treatment duration was 2.3 months (range $0.5-13.5$ ). The reasons for discontinuation of therapy were progression of lymphoma $(n=47)$, completion of 12 cycles $(n=3)$, prolonged rash despite dose interruption $(n=3)$, transplant $(n=2)$, patients' choice other than toxicity or disease progression $(n=3)$ and non-compliance $(n=1)$.

\section{Response}

Of all 59 patients treated in this study, 8 patients experienced objective response (two CR and six PR, overall response rate 14\%). The median duration of response in responders was 5.8 months (range, 1.8-11.6 months). The changes in the sum of the product of diameters of target lesions are shown as a waterfall chart in Fig 1 . This waterfall chart excludes five patients who did not have radiographic response evaluations due to clinical disease progression $(n=4)$ or poor compliance to the protocol schedules $(n=1)$.

Of 25 patients with cHL, five patients experienced PR (ORR 20\%). Responses were observed regardless of the number of regimens or prior autologous stem cell transplantation; median numbers of prior treatment regimens were 6 (range 4-7) and 4.5 (range 2-8) in 5 responders and 18 non-responders, respectively. Response rate in indolent lymphoma $(n=9)$ was $22 \%$ [one CR in small lymphocytic lymphoma (SLL), lasting for 3.5 months, and one PR in follicular lymphoma (FL), lasting for 5.8 months]. One patient with MCL achieved PR (response rate 9\%). There was no clinical response observed in T-cell lymphoma (total $n$ $=3$ ) and DLBCL (total $n=11$ ).

The median EFS duration in all patients was 2.8 months. The median EFS durations in those with cHL, DLBCL and MCL were 3.6, 1.8 and 1.9 months, respectively (Fig 2).

\section{Toxicity}

All 59 patients who received at least one dose of treatment were assessed for toxicity. All haematological toxicity, Grade 3/4 toxicities at least possibly related to the study drug, in addition to Grade $1 / 2$ toxicity at least possibly related to the study drug, seen in $\geq 5 \%$, are shown in Table III. Rash was the most common toxicity observed in this study (any Grade $53 \%$, Grade 3 in 15\%). Rash was observed in a dose-dependent manner, and the dose interruption and reduction made the continuation of the drug possible, except for three patients who had prolonged rash, leading to treatment termination. Elevations of blood 
glucose levels were also commonly observed, with any grade in 57\% and Grade 3/4 in 5\%. The Grade 4 hyperglycaemia was observed in the context of rapid disease progression and this patient did not resume treatment. All cytopenias are reported in Table III. It should be noted that this is a previously heavily treated population. The treatment was otherwise generally well tolerated.

\section{Correlative cytokine analysis during therapy}

Serum cytokines levels were measured in 36 consenting patients on days 1, 8 and 22 of the first cycle. Several of cytokine levels increased after the treatment with MK2206. The cytokine levels on both days 8 and 22 were significantly higher compared to the baseline for IL10, IL8, IP10, MCP1 and TNFa, though the clinical significance of these changes may be small (Fig 3). In contrast, none of the cytokines showed significant decrease in their levels when analyses were performed in all patients or when analysed according to histology (11 cHL, 6 DLBCL, 8 MCL, 4 FL, 3 MZL 1 SLL, and 3 PTCL). In this population of 36 patients analysed for cytokine changes, only 2 experienced clinical responses (one cHL, one FL). The changes of cytokine levels during treatment were not significantly associated with the response (comparison between patients achieving PR versus others). It should be noted, however, that this exploratory analysis is based on a very limited number of patients.

\section{Discussion}

PI3K/AKT/mTOR pathway has been considered an attractive target of therapy in lymphoma (Table IV). The first target extensively evaluated in clinical trials was mTOR, which can be inhibited by everolimus or temsirolimus. Everolimus has shown promising activity in refractory or recurrent cHL, with an overall response rate of $42 \%$ (Johnston et al, 2012b). Everolimus has also been tested in other subtypes of lymphoma, showing moderate activity. Temsirolimus may have a better clinical activity in MCL (Witzig et al, 2005). More recently, a PI3K inhibitor has been tested in clinical trials and has shown clinical activities. The first in the class drug, idelalisib, inhibits PI3K delta (PIK3CD) and has shown clinical activities in indolent lymphoma (Gopal et al, 2014) and MCL (Kahl et al, 2014). The drug was generally well tolerated, and was not associated with significant cytopenia. This drug however, seems to have limited activity in DLBCL (Flinn et al, 2013a) or Hodgkin lymphoma (Younes et al, 2013) as a single agent (Younes et al, 2013). A pan-PI3K inhibitor, IPI145, has also been tested in a relatively large phase I study, showing clinical activity in indolent lymphomas (Flinn et al, 2013b).

The AKT inhibitor MK2206 has been investigated in the treatment of solid tumours and leukaemia. The first-in-man trial of MK2206 determined that the maximum tolerated dose was $60 \mathrm{mg}$ orally on alternate days, and showed that two patients with pancreatic neuroendocrine tumours had minor response (Yap et al, 2011). In a study of MK2206 for acute myeloid leukaemia, the schedule was $200 \mathrm{mg}$ weekly and there was one response out of 19 patients treated (Konopleva et al, 2014). In that study, it was concluded that this inhibitor had insufficient clinical antileukaemic activity when given alone at tolerated doses, and alternative approaches were to be explored. 
The correlative cytokine analysis was performed in a limited number of patients in the present study. The levels of several cytokines (IL10, IL8, IP10, MCP1 and TNFa) increased after treatment with MK2206. Some of these changes may potentially be the consequence of accelerate tumour growth, but some may be due to a negative feedback loop mechanism that may be an on-target effect. A recent preclinical study has demonstrated that targeting AKT with its allosteric inhibitor AKTi1/2 resulted in paradoxical AKT phosphorylation and activation of downstream signalling in leukaemia samples (Bertacchini et al, 2014). Our result needs to be interpreted with caution given the limited number of samples analysed and relatively high family-wise error rate associated with the analyses of 29 cytokines.

The current study is the first to evaluate an agent that targets AKT in lymphoma. It should be noted that the study allowed flexible dose modification, and the toxicity, particularly rash, seems to be dose-dependent. On the other hand, there were no apparent associations observed between the final doses given and the responses. The study showed that the AKT inhibitor MK2206 can induce responses in cHL and indolent lymphoma, and thus warrants further investigation of the drug in these diseases. The single agent activity, however, seems to be low against DLBCL, T-cell lymphoma or MCL. This lack of response may be related to the increase in some cytokine levels after therapy with MK2206, as discussed above. Other possible mechanisms of resistance to the treatment with AKT inhibitors may include suboptimal inhibition of AKT phosphorylation at low concentrations or development of alternative survival pathway (Konopleva et al, 2014).

In summary, the activity of MK2206 as a single agent is, at best, modest in lymphoma. Future studies should aim at optimizing the dose and schedule of AKT inhibitors, and explore mechanism-based combination strategies with chemotherapy or other molecular target therapies.

\section{Acknowledgments}

The study was conducted with the support of Cancer Therapy Evaluation Program of National Cancer Institute, USA.

\section{References}

Bertacchini J, Guida M, Accordi B, Mediani L, Martelli AM, Barozzi P, Petricoin E 3rd, Liotta L, Milani G, Giordan M, Luppi M, Forghieri F, De Pol A, Cocco L, Basso G, Marmiroli S. Feedbacks and adaptive capabilities of the PI3K/Akt/mTOR axis in acute myeloid leukemia revealed by pathway selective inhibition and phosphoproteome analysis. Leukemia. 2014; 28:2197-2205. [PubMed: 24699302]

Biondo A, Yap TA, Yan L, Patnaik A, Fearen I, Baird RD, Papadopoulos KP, Delgado LM, Taylor A, Lupinacci L, Blackman SC, Decordova S, Tall M, Heaton S, Garrett MD, Sullivan D, Bono JSD, Tolcher AW. Phase I clinical trial of an allosteric AKT inhibitor, MK-2206, using a once weekly (QW) dose regimen in patients with advanced solid tumors. Journal of Clinical Oncology. 2011; 29 abstr 3037.

Cheson BD, Pfistner B, Juweid ME, Gascoyne RD, Specht L, Horning SJ, Coiffier B, Fisher RI, Hagenbeek A, Zucca E, Rosen ST, Stroobants S, Lister TA, Hoppe RT, Dreyling M, Tobinai K, Vose JM, Connors JM, Federico M, Diehl V. Revised response criteria for malignant lymphoma. Journal of Clinical Oncology. 2007; 25:579-586. [PubMed: 17242396]

Dreyling M, Morschhauser F, Bron D, Bouabdallah K, Vitolo U, Linton K, Van Den Neste E, Mappa S, Giurescu M, Childs BH, Zinzani PL. Preliminary results of a phase II study of single agent Bay 
80-6946, a novel PI3K inhibitor, in patients with relapsed/refractory, indolent or aggressive lymphoma. Blood. 2013; 122 abstr 87.

Engelman JA. Targeting PI3K signalling in cancer: opportunities, challenges and limitations. Nature Reviews Cancer. 2009; 9:550-562. [PubMed: 19629070]

Flinn IW, Brown JR, Byrd JC, Coutre SE, Wagner-Johnston ND, Kahl BS, Spurgeon SE, Benson DM, Peterman S, Johnson D, Li D, Dansey RD, Jahn TM, Furman RR. Final report of a phase I study of idelalisib (GS-1101) a selective inhibitor of PI3Kd, in patients with relapsed or refractory CLL. Hematological Oncology. 2013a; 31 abstr 297.

Flinn I, Patel M, Kahl BS, Horwitz SM, Foss FM, Oki Y, Porcu P, Sweeney J, Allen K, Faia K, Harris P, Dunbar J, Stern HM, Kelly P, O’Brien S. Preliminary safety and efficacy of IPI-145, a potent inhibitor of phosphoinositide-3-kinase- $\delta, \gamma$, in patients with chronic lymphocytic leukemia. Blood. 2013b; 122 abstr 677.

Georgakis GV, Younes A. From Rapa Nui to rapamycin: targeting PI3K/Akt/mTOR for cancer therapy. Expert Review of Anticancer Therapy. 2006; 6:131-140. [PubMed: 16375650]

Gopal AK, Kahl BS, de Vos S, Wagner-Johnston ND, Schuster SJ, Jurczak WJ, Flinn IW, Flowers CR, Martin P, Viardot A, Blum KA, Goy AH, Davies AJ, Zinzani PL, Dreyling M, Johnson D, Miller LL, Holes L, Li D, Dansey RD, Godfrey WR, Salles GA. PI3Kdelta inhibition by idelalisib in patients with relapsed indolent lymphoma. New England Journal of Medicine. 2014; 370:10081018. [PubMed: 24450858]

Hay N. The Akt-mTOR tango and its relevance to cancer. Cancer Cell. 2005; 8:179-183. [PubMed: 16169463]

Hirai H, Sootome H, Nakatsuru Y, Miyama K, Taguchi S, Tsujioka K, Ueno Y, Hatch H, Majumder PK, Pan BS, Kotani H. MK-2206, an allosteric Akt inhibitor, enhances antitumor efficacy by standard chemotherapeutic agents or molecular targeted drugs in vitro and in vivo. Molecular Cancer Therapeutics. 2010; 9:1956-1967. [PubMed: 20571069]

Horwitz SM, Porcu P, Flinn I, Kahl BS, Sweeney J, Stern HM, Douglas M, Allen K, Kelly P, Foss FM. Duvelisib (IPI-145), a phosphoinositide-3-kinase-d,? inhibitor, shows activity in patients with relapsed/refractory T-cell lymphoma. Blood. 2014; 124 abstr 803.

Jia S, Liu Z, Zhang S, Liu P, Zhang L, Lee SH, Zhang J, Signoretti S, Loda M, Roberts TM, Zhao JJ. Essential roles of PI(3) K-p110beta in cell growth, metabolism and tumorigenesis. Nature. 2008; 454:776-779. [PubMed: 18594509]

Johnston PB, Pinter-Brown LC, Rogerio JW, Warsi G, Chau Q, Ramchandren R. Everolimus (EVE) for relapsed/refractory classical Hodgkin lymphoma (cHL): open-label, single-arm, phase II study. Journal of Clinical Oncology. 2012a; 30 abstr 8028.

Johnston PB, Pinter-Brown L, Rogerio J, Warsi G, Chau Q, Ramchandren R. Everolimus for relapsed/ refractory classical hodgkin lymphoma: multicenter, open-label, single-arm, phase 2 study. Blood. 2012 b; 120 abstr 2740.

Kahl BS, Spurgeon SE, Furman RR, Flinn IW, Coutre SE, Brown JR, Benson DM, Byrd JC, Peterman S, Cho Y, Yu A, Godfrey WR, Wagner-Johnston ND. A phase 1 study of the PI3Kdelta inhibitor idelalisib in patients with relapsed/refractory mantle cell lymphoma (MCL). Blood. 2014; 123:3398-3405. [PubMed: 24615778]

Konopleva MY, Walter RB, Faderl SH, Jabbour EJ, Zeng Z, Borthakur G, Huang X, Kadia TM, Ruvolo PP, Feliu JB, Lu H, Debose L, Burger JA, Andreeff M, Liu W, Baggerly KA, Kornblau SM, Doyle LA, Estey EH, Kantarjian HM. Preclinical and early clinical evaluation of the oral AKT inhibitor, MK-2206, for the treatment of acute myelogenous leukemia. Clinical Cancer Research. 2014; 20:2226-2235. [PubMed: 24583795]

Li Z, Yan S, Attayan N, Ramalingam S, Thiele CJ. Combination of an allosteric Akt Inhibitor MK-2206 with etoposide or rapamycin enhances the antitumor growth effect in neuroblastoma. Clinical Cancer Research. 2012; 18:3603-3615. [PubMed: 22550167]

Molife LR, Yan L, Vitfell-Rasmussen J, Zernhelt AM, Sullivan DM, Cassier PA, Chen E, Biondo A, Tetteh E, Siu LL, Patnaik A, Papadopoulos KP, de Bono JS, Tolcher AW, Minton S. Phase 1 trial of the oral AKT inhibitor MK-2206 plus carboplatin/paclitaxel, docetaxel, or erlotinib in patients with advanced solid tumors. Journal of Hematology \& Oncology. 2014; 7:1. [PubMed: 24387695] 
Osaki M, Oshimura M, Ito H. PI3K-Akt pathway: its functions and alterations in human cancer. Apoptosis. 2004; 9:667-676. [PubMed: 15505410]

Petrich AM, Leshchenko V, Kuo PY, Xia B, Thirukonda VK, Ulahannan N, Gordon S, Fazzari MJ, Ye BH, Sparano JA, Parekh S. Akt inhibitors MK-2206 and nelfinavir overcome mTOR inhibitor resistance in diffuse large B-cell lymphoma. Clinical Cancer Research. 2012; 18:2534-2544. [PubMed: 22338016]

Renner C, Zinzani P, Gressin R, Klingbiel D, Dietrich PY, Hitz F, Bargetzi M, Mingrone W, Martinelli G, Trojan A, Bouabdallah K, Lohri A, Gyan E, Biaggi C, Cogliatti S, Bertoni F, Ghielmini M, Brauchli P, Ketterer N. A multicenter phase II trial (SAKK 36/06) of single-agent everolimus (RAD001) in patients with relapsed or refractory mantle cell lymphoma. Haematologica. 2012; 97:1085-1091. [PubMed: 22315486]

Rodon J, Dienstmann R, Serra V, Tabernero J. Development of PI3K inhibitors: lessons learned from early clinical trials. Nature Reviews Clinical Oncology. 2013; 10:143-153.

Smith SM, van Besien K, Karrison T, Dancey J, McLaughlin P, Younes A, Smith S, Stiff P, Lester E, Modi S, Doyle LA, Vokes EE, Pro B. Temsirolimus has activity in non-mantle cell non-Hodgkin's lymphoma subtypes: the University of Chicago phase II consortium. Journal of Clinical Oncology. 2010; 28:4740-4746. [PubMed: 20837940]

Vivanco I, Sawyers CL. The phosphatidylinositol 3-Kinase AKT pathway in human cancer. Nature Reviews Cancer. 2002; 2:489-501. [PubMed: 12094235]

Witzig TE, Geyer SM, Ghobrial I, Inwards DJ, Fonseca R, Kurtin P, Ansell SM, Luyun R, Flynn PJ, Morton RF, Dakhil SR, Gross H, Kaufmann SH. Phase II trial of single-agent temsirolimus (CCI-779) for relapsed mantle cell lymphoma. Journal of Clinical Oncology. 2005; 23:5347-5356. [PubMed: 15983389]

Witzig TE, Reeder CB, LaPlant BR, Gupta M, Johnston PB, Micallef IN, Porrata LF, Ansell SM, Colgan JP, Jacobsen ED, Ghobrial IM, Habermann TM. A phase II trial of the oral mTOR inhibitor everolimus in relapsed aggressive lymphoma. Leukemia. 2011; 25:341-347. [PubMed: 21135857]

Yap TA, Yan L, Patnaik A, Fearen I, Olmos D, Papadopoulos K, Baird RD, Delgado L, Taylor A, Lupinacci L, Riisnaes R, Pope LL, Heaton SP, Thomas G, Garrett MD, Sullivan DM, de Bono JS, Tolcher AW. First-in-man clinical trial of the oral pan-AKT inhibitor MK-2206 in patients with advanced solid tumors. Journal of Clinical Oncology. 2011; 29:4688-4695. [PubMed: 22025163]

Yee KW, Zeng Z, Konopleva M, Verstovsek S, Ravandi F, Ferrajoli A, Thomas D, Wierda W, Apostolidou E, Albitar M, O'Brien S, Andreeff M, Giles FJ. Phase I/II study of the mammalian target of rapamycin inhibitor everolimus (RAD001) in patients with relapsed or refractory hematologic malignancies. Clinical Cancer Research. 2006; 12:5165-5173. [PubMed: 16951235]

Younes A, Moskowitz AJ, Moskowitz CH, Fanale MA, Shustov A, Peterman S, Johnson D, Zhou L, Dansey RD, Godfrey WR, Gopal AK. Pilot phase 2 study of idelalisib, a selective inhibitor of PI3Kd, in patients with heavily pretreated hodgkin lymphoma (HL). Hematological Oncology. 2013; 31 abstr 139.

Younes A, Salles G, Bociek RG, Martinelli G, Caballero D, Barca EG, Mukherjee N, Williams L, Herbst F, Tavorath R, Kim WS. An open-label phase II study of buparlisib (BKM120) in patients with relapsed and refractory diffuse large B-cell lymphoma, mantle cell lymphoma or follicular lymphoma. Blood. 2014; 124 abstr 1718.

Yuan TL, Cantley LC. PI3K pathway alterations in cancer: variations on a theme. Oncogene. 2008; 27:5497-5510. [PubMed: 18794884]

Zent CS, LaPlant BR, Johnston PB, Call TG, Habermann TM, Micallef IN, Witzig TE. The treatment of recurrent/refractory chronic lymphocytic leukemia/small lymphocytic lymphoma (CLL) with everolimus results in clinical responses and mobilization of CLL cells into the circulation. Cancer. 2010; 116:2201-2207. [PubMed: 20166206] 


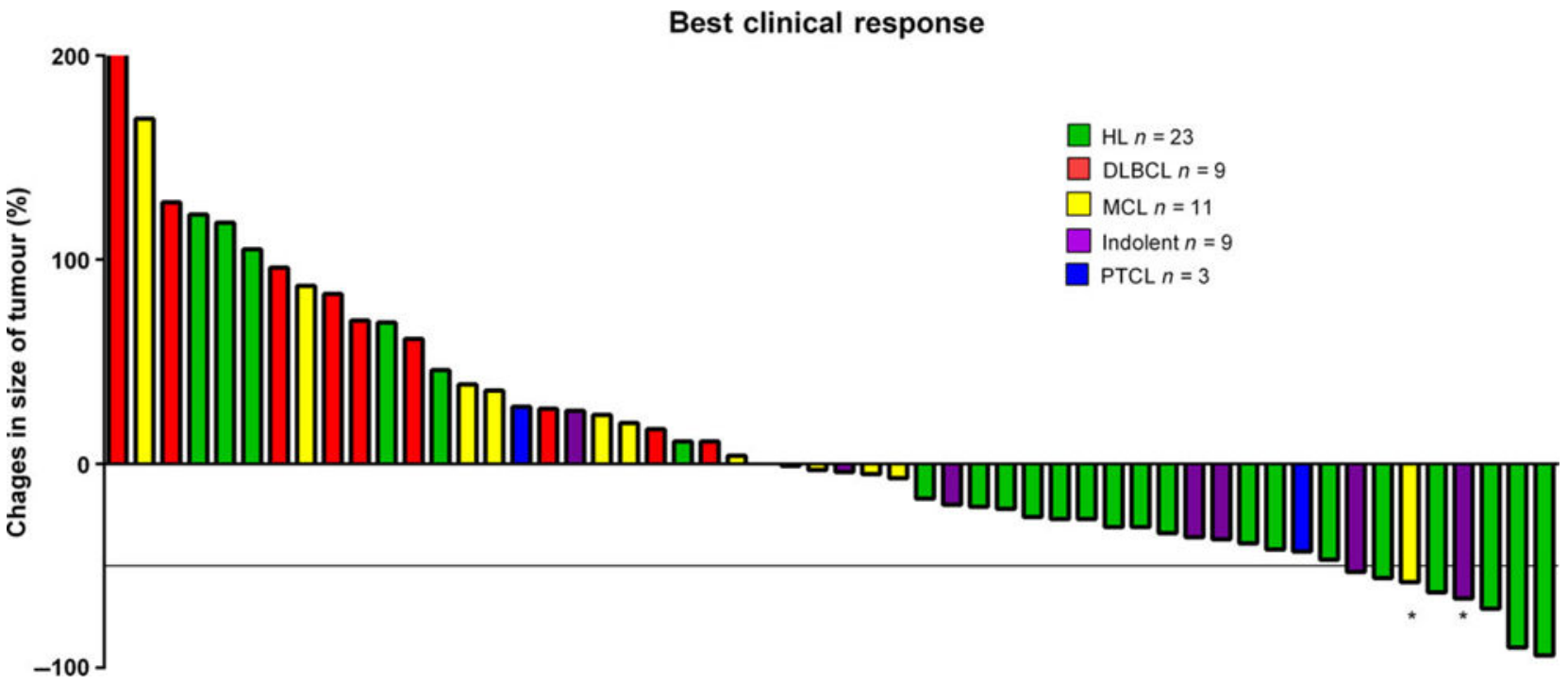

Fig 1.

The waterfall chart showing the changes of tumour size. The figure shows 54 patients. Five patients that did not undergo formal tumour measurement after treatment. *Indicates complete metabolic response defined by fluorodeoxyglucose-positron emission tomography scan. HL, Hodgkin lymphoma; DLBCL, diffuse large B-cell lymphoma; MCL, mantle cell lymphoma; AITL, angioimmunoblastic T-cell lymphoma. 


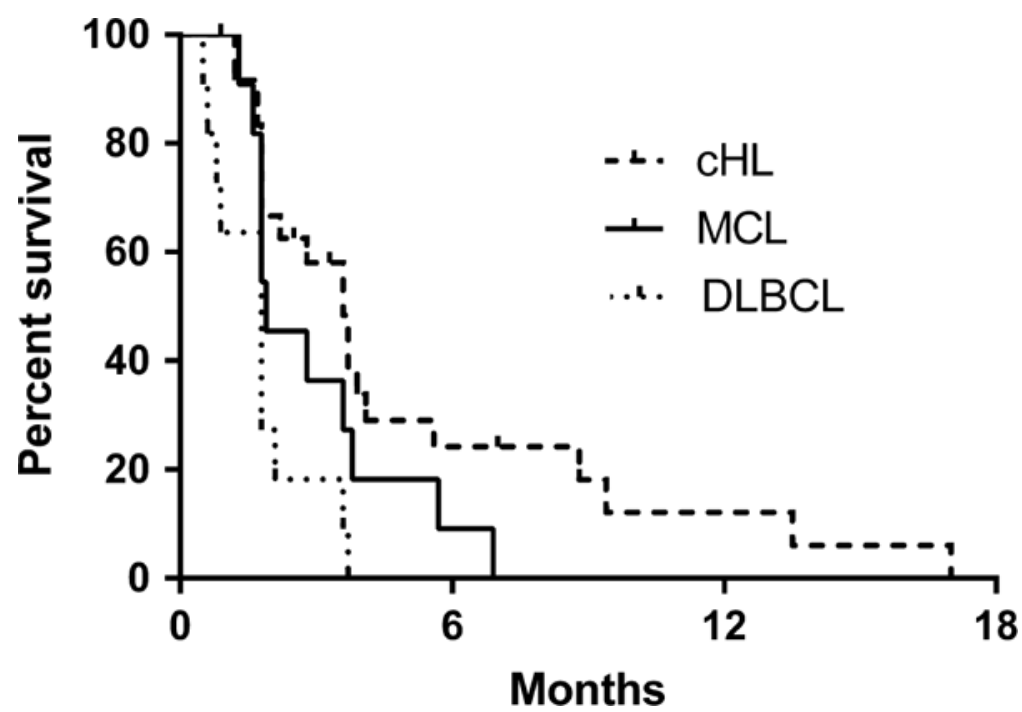

Fig 2.

Progression free survival. The curves are for classical Hodgkin lymphoma (cHL, $n=25)$, diffuse large B-cell lymphoma (DLBCL, $n=11$ ) and mantle cell lymphoma (MCL, $n=7$ ). Other subtypes had $<5$ patients in each cohort and thus, the curves were not generated for them. 
IL10

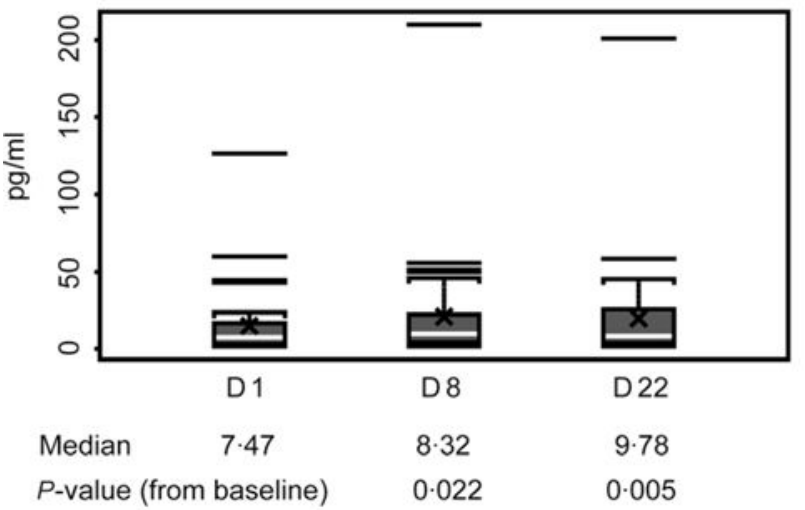

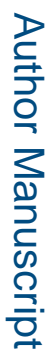

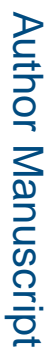

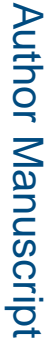

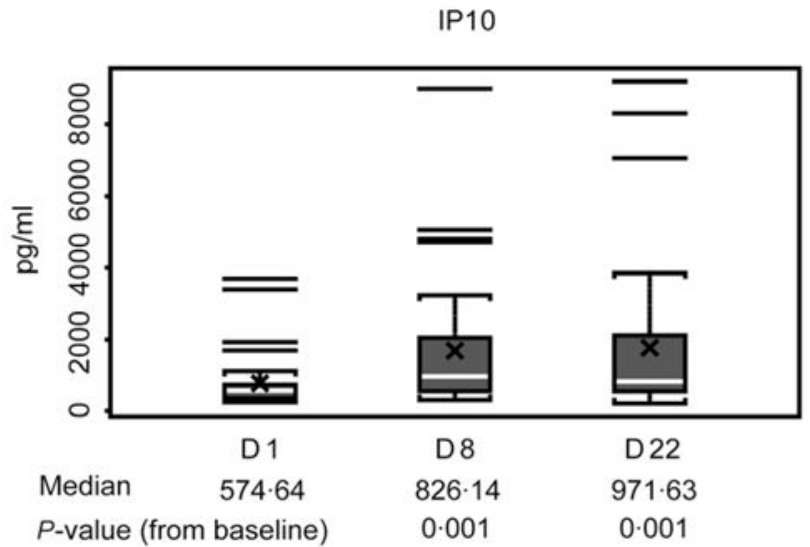

$\mathrm{TNF} \alpha$

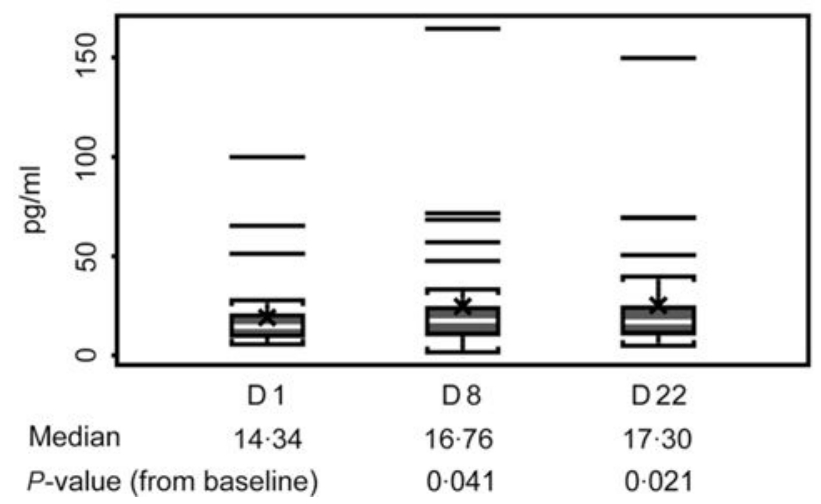

Fig 3.

Changes in cytokine levels during therapy.
IL8

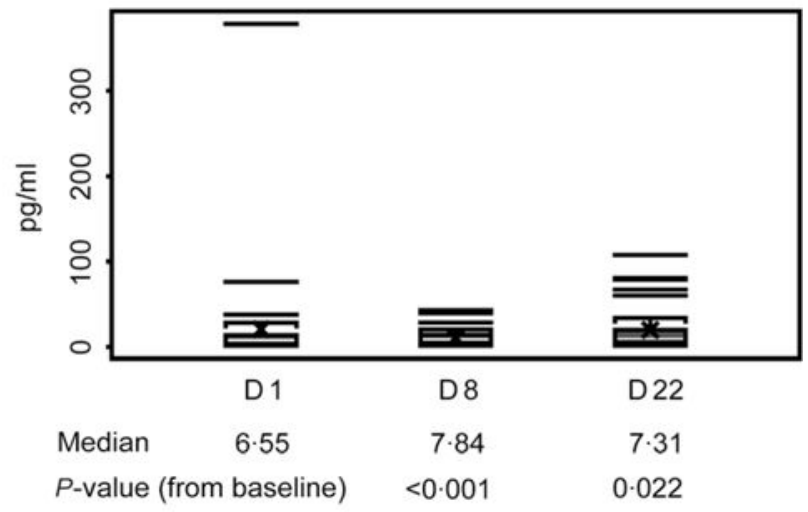

MCP1

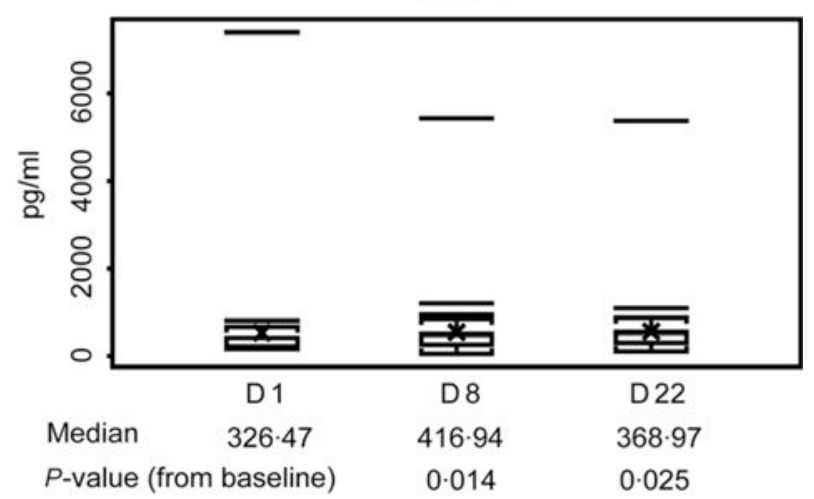




\section{Table I}

MK2206 dosing in lymphoma patients.

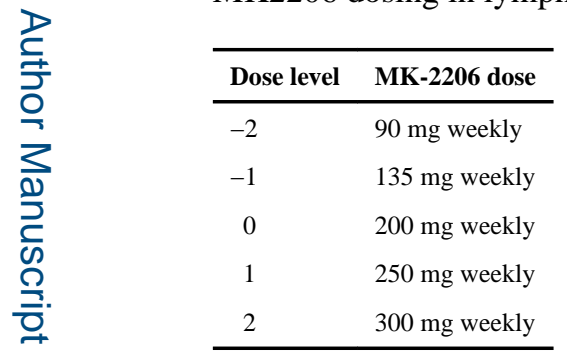

吝

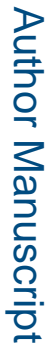

롤

Br J Haematol. Author manuscript; available in PMC 2017 January 30. 
Table II

Patient characteristics.

\begin{tabular}{lll}
\hline Characteristics & & $N$ (total 59) \\
\hline Age (years) & Median (range) & $57(20-81)$ \\
Sex & Male/female & $39 / 20$ \\
Histology & Classical Hodgkin lymphoma & 25 \\
& Diffuse large B-cell lymphoma & 11 \\
& Mantle cell lymphoma & 11 \\
& Follicular lymphoma & 4 \\
& Marginal zone B-cell lymphoma & 3 \\
& Small lymphocytic lymphoma & 2 \\
& Angioimmunoblastic T-cell lymphoma & 2 \\
& Peripheral T-cell lymphoma, not otherwise specified & 1 \\
Median number of prior regimens (range) & $4(1-10)$ \\
\hline
\end{tabular}




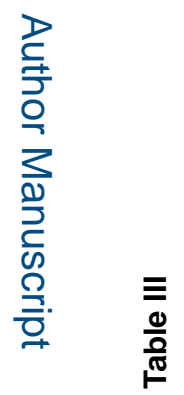

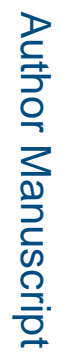

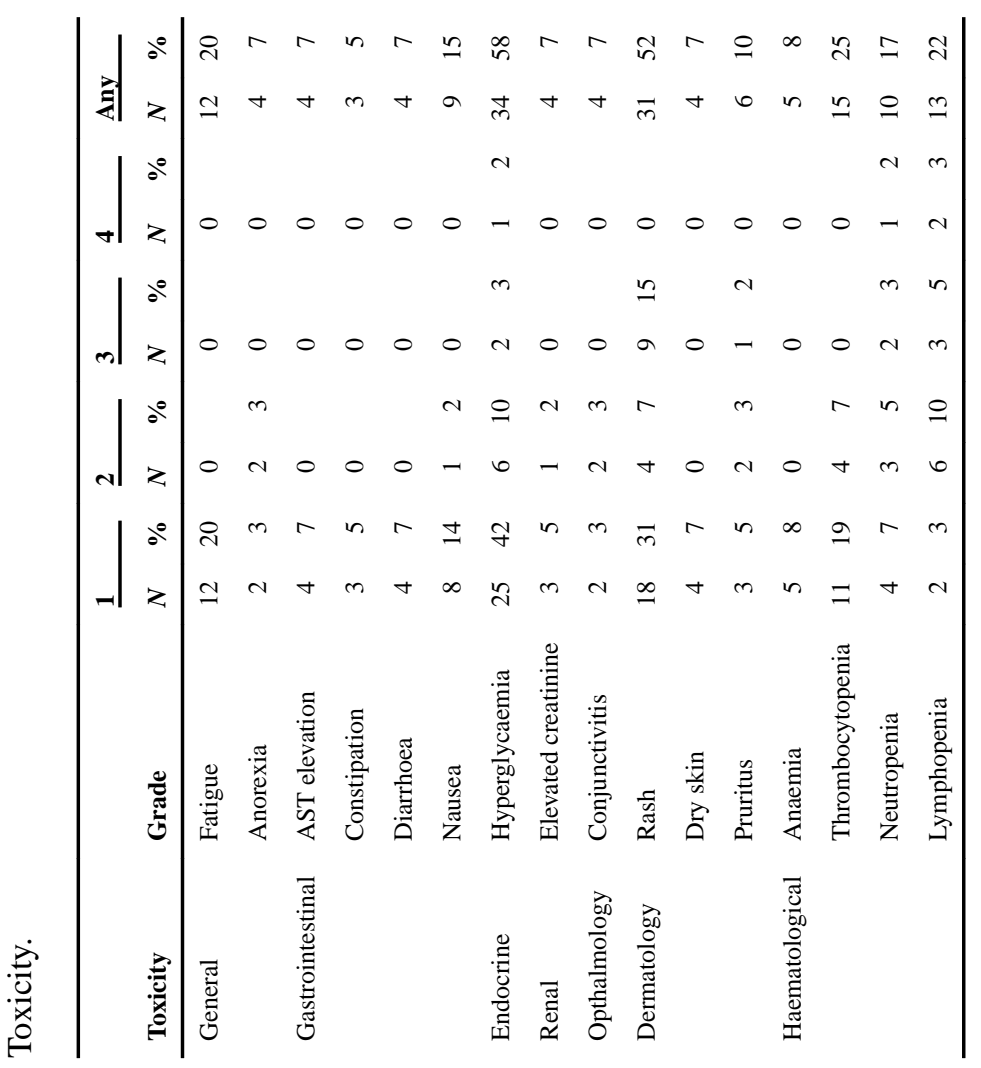




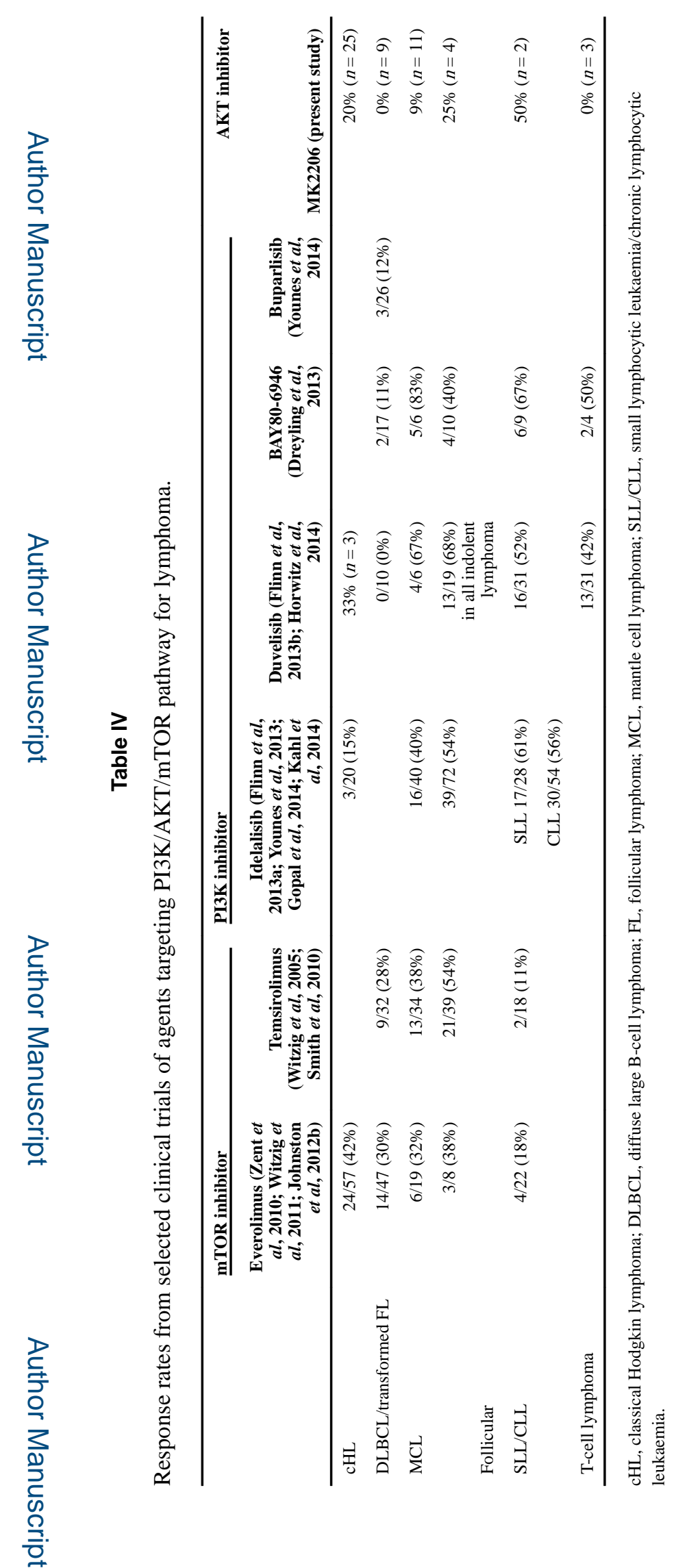

Br J Haematol. Author manuscript; available in PMC 2017 January 30. 